\title{
Inactivation of p21-Activated Kinase 2 (Pak2) Inhibits the Development of Nf2- Deficient Malignant Mesothelioma
}

Eleonora Sementino ${ }^{1 *}$, Yuwaraj Kadariya ${ }^{1 *}$, Mitchell Cheung ${ }^{1}$, Craig W. Menges ${ }^{1}$, Yinfei $\operatorname{Tan}^{2}$, Anna-Mariya Kukuyan ${ }^{1}$, Ujjawal Shrestha ${ }^{1}$, Sofiia Karchugina ${ }^{1}$, Kathy Q. Cai ${ }^{3}$, Suraj Peri ${ }^{4}$, James S. Duncan ${ }^{1}$, Jonathan Chernoff ${ }^{1}$, and Joseph R. Testa ${ }^{1,2}$

${ }^{1}$ Cancer Biology Program, ${ }^{2}$ Genomics Facility, ${ }^{3}$ Histopathology Facility and ${ }^{4}$ Bioinformatics and Biostatistics Facility, Fox Chase Cancer Center, Philadelphia, Pennsylvania.

Running Title: Pak2 loss inhibits Nf2-related mesothelioma formation

Key Words: Mesothelioma; conditional knockout mice; Nf2/merlin; PAK; Cdkn2a; EMT; Wnt signaling

Correspondence: Joseph R. Testa, Ph.D., Fox Chase Cancer Center, 333 Cottman Avenue, Philadelphia, PA 1911; Phone: (215) 728-2610; Fax: (215) 214-1619; Email:

joseph.testa@fccc.edu

\section{Conflict of Interest Statement}

JRT has provided legal consultation regarding genetic aspects of mesothelioma. The remaining authors have no potential conflicts of interest with regard to the publication of this work.

${ }^{*}$ These authors contributed equally to this work. 


\section{Abstract}

Malignant mesotheliomas (MM) show frequent somatic loss of the NF2 tumor suppressor gene. The NF2 product, Merlin, is implicated in several tumor-related pathways, including p21activated kinase (PAK) signaling. Merlin is both a phosphorylation target for PAK and a negative regulator of this oncogenic kinase. Merlin loss results in PAK activation, and PAK inhibitors hold promise for the treatment of NF2-deficient tumors. To test this possibility in an in vivo genetic system, Nf2 $2^{f / f} ; C d k n 2 a^{f / f}$ mice were crossed to mice with conditional knockout of Pak2, a highly expressed group I Pak member. Cohorts of these animals were injected in either the thoracic or peritoneal cavities with adeno-Cre virus to delete floxed alleles in the mesothelial lining. Loss of Pak2 resulted in a markedly decreased incidence and delayed onset and progression of pleural and peritoneal MMs in Nf2;Cdkn2a-deficient $(N C)$ mice, as documented by Kaplan-Meier survival curves and in vivo bioluminescent imaging. RNA-seq revealed that MMs from NC;Pak2-/- mice showed downregulated expression of genes involved in several oncogenic pathways (Wnt, Akt) when compared to MMs from mice retaining Pak2. Kinome profiling showed that, as compared to NC MM cells, NC;Pak2 $2^{-/-} \mathrm{MM}$ cells had multiple kinase changes indicative of an epithelial to mesenchymal transition. Collectively, these findings suggest that $N C ; P a k 2^{-/-}$MMs adapt by reprogramming their kinome and gene signature profiles to bypass the need for PAK activity via the activation of other compensatory oncogenic kinase pathways. The identification of such secondary pathways offers opportunities for rational combination therapies to circumvent resistance to anti-PAK drugs. 


\section{Introduction}

Malignant mesotheliomas (MMs) are medically unresponsive cancers of the membranes lining the serous cavities. MMs often occur after chronic exposure of mesothelial cells to asbestos fibers (1). MM causes more than 3,000 deaths annually in the U.S., and a significant increase in MM incidence is predicted in certain developing countries where asbestos usage is increasing at an alarming rate and where protection of workers is minimal.

Genetically, MM is characterized by frequent somatic loss/inactivation of certain tumor suppressor genes, prominent among them being BAP1, NF2, and CDKN2A/B (2-10). NF2 mutations and loss of Merlin expression have been reported in up to $\sim 55 \%$ of MM cell lines (5). Among pleural MM tumors characterized by The Cancer Genome Atlas (TCGA), monoallelic deletions of NF2 were observed in $34 \%$ of samples and biallelic inactivation in another $40 \%$ of tumors, with many of the latter harboring mutations of one allele (10). Underscoring the relevance of NF2 inactivation to MM pathogenesis, heterozygous Nf2 knockout mice treated with asbestos develop MM at a significantly higher frequency and markedly accelerated rate than their wild-type counterparts $(6,11)$. Moreover, in one of these studies, 9 of $9 \mathrm{MM}$ cell lines established from neoplastic ascites of $N f 2^{+/-}$mice exhibited loss of the wild-type $N f 2$ allele, and expression of the Nf2 protein product, Merlin, was absent in these cells (6).

Merlin has been implicated in various tumor-related signaling pathways, prominent among them being p21-activated kinase (Pak) and Hippo signaling. Merlin regulates the protein kinases Mst1 and Mst2 (mammalian sterile 20-like 1 and -2; a.k.a. serine/threonine protein kinase Stk4 and Stk3) and the serine/threonine kinases Lats1 and -2 (large tumor suppressor 1 and -2). Merlin and each of these kinases are components of the highly conserved Hippo signaling pathway, which regulates organ size in Drosophila and mammals. Combined Mst1/2 deficiency in the liver results in loss of inhibitory phosphorylation of the downstream oncoprotein Yap1 and development of hepatocellular carcinoma (12). Nf2-deficient phenotypes in multiple tissues were suppressed 
by heterozygous deletion of Yap1, suggesting that Yap is a major effector of Merlin in growth regulation. The Hippo tumor-suppressive signaling pathway has also been connected with Merlindeficient MM $(13,14)$. Other work has shown that Merlin suppresses tumorigenesis by activating upstream components of the Hippo pathway by inhibiting the E3 ubiquitin ligase CRL4(DCAF1) (15).

Merlin is regulated by phosphorylation, with hypophosphorylated Merlin being the growthinhibitory, functionally active tumor suppressor form, whereas hyperphosphorylated Merlin is growth-permissive $(16,17)$. PAK directly phosphorylates Merlin at serine residue 518 , a site that regulates Merlin activity and localization $(18,19)$. Such phosphorylation of Merlin weakens its head-to-tail self-association and its association with the cytoskeleton (20). Furthermore, functional analysis of serine 518 phosphorylation has demonstrated that expression of a phospho-mimic mutant (Merlin S518D) caused striking changes in cell proliferation and shape, stimulating the creation of filopodia (21). These results strongly suggest that Merlin's growth and motility suppression functions are attenuated following phosphorylation by Pak. Moreover, it is noteworthy that many MM tumors that lack NF2 mutations nevertheless show functional inactivation of Merlin via constitutive phosphorylation of Ser518, in some cases as a result of inhibition of a Merlin phosphatase (22).

PAKs are serine/threonine protein kinases that are binding partners for the small GTPases Cdc42 and Rac, and they represent one of the most highly conserved effector proteins for these enzymes (23). Mammalian tissues contain six Pak isoforms: group I (Pak1, -2, and -3) and group 2 (Pak4, -5, and -6). These two groups differ substantially in form and function, and only group I Paks appear to be involved in Merlin signaling (24). Group I Paks, in particular Pak1, have oncogenic properties when expressed at high levels. In most settings, expression of Pak1 stimulates cell proliferation, survival, and motility $(24,25)$. Group I Paks are frequently activated in human MM tumors, and genetic or pharmacologic inhibition of Paks is sufficient to inhibit MM cell proliferation and survival (26). Importantly, Merlin is more than just a target for Pak; it is also a 
negative regulator of this kinase. Merlin binds to and inactivates Pak1, and loss of Merlin results in the activation of Pak (20). These results suggest that the growth and motility abnormalities of Nf2-null cells might in part be attributed to the activation of Pak and its downstream targets. These data also suggest that inhibitors of Pak might be useful in switching off such signaling pathways. We hypothesized that loss of Pak activity would counteract some aspects of Nf2/Merlin loss-offunction by compromising key downstream oncogenic signaling pathways in mesothelial cells. To test this possibility, we crossed $N f 2^{f / f} ; C d k n 2 a^{f / f}$ mice to mice with conditional deletion of Pak2, which encodes the most highly expressed group I Pak isoform in most tissues. Cohorts of these animals were then injected in either the thoracic or peritoneal cavities with adeno-Cre virus to delete floxed alleles in the mesothelial lining, with the goal being to determine if Pak2 loss diminishes $\mathrm{MM}$ onset and/or progression. We show that loss of Pak2 indeed delays MM tumorigenesis, though studies employing multiplexed kinase inhibitor beads and mass spectrometry (MIB/MS) and RNA-seq technologies revealed that MM cells ultimately reprogram their kinome and gene signature profiles to bypass the need for Pak2 activity. The identification of such secondary pathways offers opportunities for the rational design of combination therapies to circumvent resistance to anti-Pak drugs.

\section{Materials and Methods}

\section{Mouse strains}

LucR;Nf2 $2^{f / f} ; C d k n a^{f / f}$ mice in FVB/N genetic background (27), a kind gift of Dr. Anton Berns, were maintained in our laboratory in a mixed FVB/N $\times 129 / \mathrm{Sv}$ background. The floxed Cdkn2a locus permits excision of exon 2, resulting in inactivation of both $\mathrm{p} 16$ (Ink4a) and p19(Arf) tumor suppressors. Pak2 ${ }^{f / f}$ mice in a C57BL/6J background (28) were crossed a minimum of five generations to $\mathrm{Nf}^{\mathrm{fff}} ; \mathrm{Cdkna}^{\mathrm{f} / \mathrm{f}}$ mice in a FVB/N $\times 129 / \mathrm{Sv}$ background. All mouse studies were 
performed in accordance with protocol \#18-03 approved by the Fox Chase Cancer Center (FCCC) Institutional Animal Care and Use Committee (IACUC).

\section{Adeno-Cre injections}

For studies involving intrathoracic (IT) injections of adeno-Cre virus, animals with $N f 2^{f / f} ; C d k n a^{f / f} ; P a k 2^{+/+}$and $N f 2^{f / f} ; C d k n a^{f / f} ; P a k 2^{f / f}$ genotypes were divided into two cohorts with equivalent numbers of male and female mice in each group. For intraperitoneal (i.p.) injection studies, animals with $N f 2^{f / f} ; C d k n a^{f / f}$ and $N f 2^{f / f} ; C d k n a^{f / f} ; P a k 2^{f / f}$ genotypes were again divided into two cohorts as above. Ad5CMVCre (adeno-Cre) virus was purchased from the Viral Vector Core of the University of lowa. At 8-10 weeks of age, all mice were injected either IT or i.p. with adenoCre virus (50 $\mu$ l of 3-6 $\times 10^{10}$ PFU) in PBS, with approximately equal numbers of mice of each gender in each cohort. Expression of adeno-Cre results in the removal of the floxed exons in the Nf2, Cdkn2a, and Pak2 loci, resulting in the following genotypes in adeno-Cre-infected cells: $N f 2^{N \Delta} ; C d k n 2 a^{N \Delta}$ and $N f 2^{N \Delta} ; C d k n 2 a^{N \Delta} ; P a k 2^{N \Delta}$, and the corresponding mice are referred to as $N C ; P^{w t}$ and $N C ; P^{-/-}$mice hereafter). All mice were closely monitored for tumor formation over a period of up to 12 months. Mice were monitored daily and were immediately sacrificed by $\mathrm{CO}_{2}$ inhalation upon signs of pain/distress or illness as judged by lethargic behavior, weight loss or bloating, difficulty in breathing, hunched posture, rough hair coat, dehydration or detectable tumor volume approaching $10 \%$ of overall body weight. Tissues of all organs of the pleural and peritoneal cavities were collected from sacrificed mice, and tumor specimens were subjected to histopathological assessment by an experienced animal pathologist (K.Q.C.) of FCCC's Histopathology Facility, a core service supported by our NCl Cancer Center Support Grant. Portions of tumors were also saved in both O.C.T. Compound and RNAlater Solution (Thermo Fisher, Waltham, MA) and immediately frozen at $-80^{\circ} \mathrm{C}$ for subsequent study. When possible, portion of the tumor was also disaggregated and cultured to generate tumor cell lines. 


\section{Detection of tumors and statistical considerations}

Survival curves for $N C ; P^{w t}$ versus $N C ; P^{-/-}$mice were compared using one-sided, log-rank tests. Kaplan-Meier plots were used to display time to tumor detection among the two separate cohorts for both IT and i.p. injection studies.

\section{Tumor histopathology, immunohistochemistry and RT-PCR}

Tumor tissues were paraffin embedded, sectioned and deparaffinized, followed by staining of sections with hematoxylin and eosin (H\&E) for histopathologic evaluation. Other sections were for immunohistochemistry (IHC), performed using standard methods. To confirm the diagnosis of MM, IHC was performed for various MM markers, including mesothelin, detected with D-16 antibody (Santa Cruz Biotechnology, Dallas, TX), and cytokeratin 8, detected with TROMA-1 antibody (DSHB, University of lowa, lowa City, IA). To evaluate tumor cell proliferation, IHC staining was performed with antibodies for Ki-67 (Dako/Agilent, Santa Clara, CA). In some tumors, reverse transcription-PCR (RT-PCR) analysis was also performed to confirm the diagnosis of $\mathrm{MM}$, using primers for the MM markers Wt1 and Msln (mesothelin). Specific primers used for RT-PCR are shown in Supplemental Table S1.

\section{Preparation of luciferin and in vivo bioluminescent Imaging (BLI)}

LucR;Nf2 ${ }^{f f f} ; C d k n a^{f / f}$ mice were crossed to Pak2 ${ }^{f / f}$ mice to generate offspring with different Pak2 genotypes $\left({ }^{+/+},+/ f, f / f\right)$, which at 8-10 weeks of age were injected IT with adeno-Cre virus. In addition to excising the floxed Nf2, Cdkna, and Pak2 alleles in mesothelial cells lining the pleural cavity, expression of Cre recombinase also removes a floxed polyadenylation acid sequence before the ORF of the luciferase reporter transgene $(L u c R)$, thereby permitting luciferase expression for monitoring tumor progression. Beginning at 6-7 weeks after injecting with adenoCre virus, littermates with different genotypes were injected i.p. with $150 \mathrm{mg}$ of filtered D-Luciferin, Firefly, potassium salt (Caliper Life Sciences) in PBS per kg mouse body weight 10 minutes before 
imaging. BLI scans were acquired using an IVIS Spectrum Imaging System (Caliper Life Sciences) as described (29) to assess the presence and relative size of tumors, as indicated by the intensity of luminescent signals detected. The same mice were imaged weekly until tumors began to form. The experiment was repeated four times.

\section{Preparation of lentivirus expressing shRNA against Pak2}

A Tet-pLKO-puro plasmid was a gift from Dmitri Wiederschain (Addgene, plasmid \# 21915). The shRNAs targeting mouse Pak2 were created by the cloning of annealed forward and reverse oligos synthesized based on information provided at the Broad Institute's website (https://portals.broadinstitute.org/gpp/public/). The clone numbers and target sequences are as follows: mouse shPak2 \#70 (TRCN0000432870): TTCGGATGAGCAGTACCATTT; mouse shPak2 \#85 (TRCN0000417285): ATGATTGATGTAGCTCTTTAC. The shRNAs was cloned as previously described (30). Lentivirus was produced by transfecting $293 \mathrm{~T}$ cells with the two different Tet-inducible shPak2, or control shGFP, and the packaging plasmids pMD2G and pPax2, using Lipofectamine 2000 transfection reagent (11668019; Thermo Fisher). After 24 h and 48 h, virus particles were collected, filtered through a $0.45-\mu \mathrm{m}$ PES filter, and then used to infect cell lines for experiments described below.

\section{In vivo model to assess lung tumor burden of MM cells following knock down of Pak2}

In this experiment, we used asbestos-induced mouse MM cells (MM87) from $\mathrm{Nf2}^{+/-}$ ;Cdkn2a ${ }^{+/-}$mice (31). The MM87 cells were infected with four separate tet-inducible lentiviruses against Pak2 to assess knockdown of Pak2. The clones with the most robust knockdown of Pak2

were expanded, and each clone was injected into the tail vein of three NSG mice $\left(0.5 \times 10^{6}\right.$ cells/mouse), followed by i.p. administration of doxycycline beginning after 7 days and then every 2 days thereafter. Animals were sacrificed on day 21, and then the lungs were harvested for 
histopathological assessment of tumor colonization. An unpaired t-test with Welch's correction was used to determine the statistical significance of the data.

\section{Immunoblot analysis and antibodies}

For immunoblotting, protein lysates were prepared as previously described (31). Lysates (30-50 $\mathrm{\mu g} / \mathrm{sample})$ were loaded on gels, transferred to nitrocellulose membranes (1620115, BioRad, Hercules, CA), and probed with anti-Nf2 (D1D8, 6995, 1:4000), anti-Pak2 (2608, 1:2000), anti-Akt (9272, 1:2000), anti-phospho (p)-Akt (Ser473) (B9E)XP (4060, 1:4000), anti-p44/42 MAPK (Erk1-2) (9102, 1:2000), Pdgfra (D1E1E) (XP 3174, 1:2000), Pdgfrß (C82A3) (4564, 1:2000), anti-Limk1 (3842, 1:1000), anti-MKK6 (9264, 1:1000), anti Ddr1 (D1G6) (XP 5583, 1:1000), E-Cadherin (24E10, 3195, 1:1000), anti-Slug (C19G7, 9585, 1:1000), anti-Snail (C15D3, 3879, 1:1000), anti-Stat3 (124H6, 9139, 1:5000), anti-p-Stat3 (Tyr705) (D3A7, XP 9145, 1:1000), anti-Fyn (4023, 1:1000), anti-Met (25H2, 3127, 1:1000), anti-Jak1 (6G4, 3344, 1:1000), and antiN-Cadherin (D4R1H, XP 13116, 1:1000) from Cell Signaling Technology (Danvers, MA); antiphospho-Pak1-2-3 (pSer141) (44-940G, 1:2000) from Invitrogen/Thermo Fisher Scientific (Carlsbad, CA); recombinant anti-p16Ink4a (ab211542, 1:1000) from Abcam (Cambridge, MA); anti-p19Arf (5-C3-1) (sc-32748, 1:500), anti-p-Erk (E-4) (sc-7383, 1:2000), anti-Gapdh (6C5, sc32233, 1:50,000), anti- $\beta$-catenin (E-5) (sc-7963, 1:1000) and anti- $\beta$-actin (C4, sc-47778, 1:50,000) from Santa Cruz Biotechnology, and anti-DDR2, Clone 2B12.1, MABT322, 1:1000. Anti-Rabbit IgG, peroxidase-linked species-specific whole antibody (from donkey), secondary antibody (45-000-682, 1:5000) and anti-Mouse lgG, peroxidase-linked species-specific whole antibody (from sheep) secondary antibody (45-000-679, 1:5000-50000 depending on the primary antibody) were both from Fisher Scientific (Waltham, MA). Immunoblots were imaged using Immobilon Western Chemiluminescent HRP Substrate (ECL) (WBKLS0500, MilliporeSigma, Ontario Canada). 


\section{Migration assay}

In vitro migration of $\mathrm{MM}$ cells from $N C ; P^{w t}$ mice and $N C ; P^{-/-}$mice was measured using a Transwell Multiwell Plate with Polyester Membrane Inserts (Corning, Edison, NJ). In the upper compartment of each well, $8.0 \times 10^{3}$ cells/well were seeded in serum-free DMEM medium, and in the lower compartment we placed DMEM medium containing $10 \%$ serum. Cells were incubated at $37^{\circ} \mathrm{C}$ in a humidified $5 \% \mathrm{CO}_{2}$ incubator for 22 hours, and then the permeable insert was stained according to the manufacturer's recommendations. The migrating cells on the underside of the membrane were fixed and stained with Diff-Quik solution.

\section{MTS assay}

Lentivirus particles harboring two different Tet-inducible shPak2 constructs (\#70, \#85), or control shGFP, were used to infect pleural NC; $P^{w t} \mathrm{MM}$ cell line \#2. The cells were seeded on a 6well plate and allowed to proliferate to approximately $50 \%$ confluency. Then virus particles and polybrene (sc-134220; Santa Cruz) at a concentration of $2 \mu \mathrm{g} / \mathrm{ml}$ were added to the plate, which was then spun down for $2 \mathrm{~h}$ at $2000 \mathrm{rpm}$ and incubated for $24 \mathrm{~h}$ at $37^{\circ} \mathrm{C}$ in a humidified $5 \% \mathrm{CO}_{2}$ incubator. The cells were then selected in fresh media containing puromycin $(4 \mu \mathrm{g} / \mathrm{ml})$ for 3 days. When the selection was completed, the cells were treated with doxycycline for $24 \mathrm{~h}$ and seeded in 96 -well plates at 500 cells/well. The following day, the cells were refed with fresh media containing puromycin (4 $\mathrm{gg} / \mathrm{ml})$ and doxycycline (Sigma, D9891; stock $1 \mathrm{mg} / \mathrm{ml}$, diluted 1:1000), which was also added to the cells daily thereafter. Cell viability was assessed at 2, 4, 5 and $6 \mathrm{~d}$ using a CellTiter 96® AQueous One Solution Cell Proliferation Assay (MTS) (G3582; Promega, Madison, WI). Cells were incubated with the MTS reagent 3-4 h, and the OD value at $490 \mathrm{~nm}$ was measured, using a 96-well microplate reader (BioRad, Santa Monica, CA).

\section{RNA-seq and gene set enrichment analyses}


Tumor cell RNA was isolated in Trizol and purified using RNeasy columns (Qiagen, Germantown, MD). An initial RNA-seq analysis was performed on a small set of MMs, with mRNAseq libraries prepared as previously described (32), followed by loading onto an Illumina NextSeq 500 sequencer. RNA-seq analysis was performed on an expanded set of MMs by Novogene (Sacramento, CA), using its Illumina NovaSeq 6000 platform. The Fastq files were aligned to the mm10 mouse genome using the STAR RNA-seq aligner. Raw sequence counts for each gene were produced with HTseq (https://htseq.readthedocs.io), and differentially expressed genes were determined using DESeq2 (33) For functional enrichment analysis, genes identified as differentially expressed with nominal $p$-value $<0.5$ were ranked by fold-change and mapped to human genes using R biomaRt (34). Next, these genes were analyzed using the GSEAPreranked method of Gene Set Enrichment Analysis (GSEA) (35), with "classic" enrichment statistic, applied to the curated canonical pathways (c2cp) and Gene Ontology gene sets from the Molecular Signature Database (MSigDB). Heatmaps were made using pheatmap library available through Bioconductor (https://www.bioconductor.org). Raw sequencing data is in the process of being deposited in the GEO repository.

\section{MIBs preparation and chromatography}

In an attempt to gain an unbiased and more comprehensive view of Merlin signaling, kinome reprogramming analysis was performed using MIB/MS as previously described (36). In brief, cells were lysed on ice in buffer containing 50 mM HEPES (pH 7.5), 0.5\% Triton X-100, 150 mM NaCl, 1 mM EDTA, 1 mM EGTA, 10 mM sodium fluoride, $2.5 \mathrm{mM}$ sodium orthovanadate, 1X protease inhibitor cocktail (Roche), and 1\% each of phosphatase inhibitor cocktails 2 and 3 (Sigma). Particulate was removed by centrifugation of lysates at $21,000 \mathrm{~g}$ for $15 \mathrm{~min}$ at $4^{\circ} \mathrm{C}$ and filtration through $0.45 \mu \mathrm{m}$ syringe filters. Protein concentrations were determined by BCA analysis (Thermo Scientific). Endogenous kinases were isolated by flowing lysates over kinase inhibitorconjugated Sepharose beads (purvalanol B, VI16832, PP58 and CTx-0294885 beads) in $10 \mathrm{ml}$ 
gravity-flow columns. After 2x10-ml column washes in high-salt buffer and 1x10-ml wash in lowsalt buffer (containing 50 mM HEPES (pH 7.5), 0.5\% Triton X-100, 1 mM EDTA, 1 mM EGTA, 10 $\mathrm{mM}$ sodium fluoride, and $1 \mathrm{M} \mathrm{NaCl}$ or $150 \mathrm{mM} \mathrm{NaCl}$, respectively, retained kinases were eluted from the column by boiling in $2 \times 500 \mu$ of $0.5 \%$ SDS, $0.1 \mathrm{M}$ TrisHCl $(\mathrm{pH} \mathrm{6.8),} \mathrm{and} \mathrm{1 \%} \mathrm{2-}$ mercaptoethanol. Eluted peptides were reduced by incubation with $5 \mathrm{mM} \mathrm{DTT}$ at $65^{\circ} \mathrm{C}$ for $25 \mathrm{~min}$, alkylated with $20 \mathrm{mM}$ iodoacetamide at room temperature for $30 \mathrm{~min}$ in the dark, and alkylation was quenched with DTT for $10 \mathrm{~min}$. Samples were concentrated to approximately $100 \mu \mathrm{l}$ with Millipore $10 \mathrm{kD}$ cutoff spin concentrators. Detergent was removed by chloroform/methanol extraction, and the protein pellet was resuspended in $50 \mathrm{mM}$ ammonium bicarbonate and digested with sequencing-grade modified trypsin (Promega) overnight at $37^{\circ} \mathrm{C}$. Peptides were cleaned with PepClean C18 spin columns (Thermo Fisher Scientific), dried in a speed-vac, resuspended in $50 \mu \mathrm{l}$ of $0.1 \%$ formic acid, and extracted with ethyl acetate (10:1 ethyl acetate: $\mathrm{H}_{2} \mathrm{O}$ ). Briefly, $1 \mathrm{~mL}$ ethyl acetate was added to each sample, vortexed, and centrifuged at maximum speed for $5 \mathrm{~min}$, and then removed. This process was repeated 4 more times. After removal of ethyl acetate following the fifth centrifugation, samples were placed at $60^{\circ} \mathrm{C}$ for $10 \mathrm{~min}$ to evaporate residual ethyl acetate. The peptides were then dried in a speed vac, and subsequent LC-MS/MS analysis was performed.

\section{Nano-LC-MS/MS}

Proteolytic peptides were resuspended in $0.1 \%$ formic acid and separated with a Thermo Scientific RSLC Ultimate 3000 on a Thermo Scientific Easy-Spray C18 PepMap $75 \mu \mathrm{m}$ x $50 \mathrm{~cm}$ C-18 $2 \mu \mathrm{m}$ column with a 240 min run time on a gradient of $4-25 \%$ acetonitrile with $0.1 \%$ formic acid at $300 \mathrm{~nL} / \mathrm{min}$ at $50^{\circ} \mathrm{C}$. Eluted peptides were analyzed by a Thermo Scientific Q Exactive plus mass spectrometer utilizing a top 15 methodology in which the 15 most intense peptide precursor ions were subjected to fragmentation. The AGC for MS1 was set to $3 \times 10^{6}$ with a 
maximum injection time of $120 \mathrm{~ms}$, the AGC for MS2 ions was set to $1 \times 10^{5}$ with a maximum injection time of $150 \mathrm{~ms}$, and the dynamic exclusion was set to $90 \mathrm{~s}$.

\section{Data processing for kinome profiling analysis}

MIB/MS was performed in biological triplicates for each condition and analyzed by LCMS/MS in technical duplicates. Raw data analysis of MIB/MS experiments was performed using MaxQuant software 1.6.1.0 and searched using Andromeda 1.5.6.0 against the Swiss-Prot human protein database (downloaded on July 26, 2018). The search was set up for full tryptic peptides with a maximum of two missed cleavage sites. All settings were default and searched using acetylation of protein $\mathrm{N}$-terminus and oxidized methionine as variable modifications. Carbamidomethylation of cysteine was set as fixed modification. The precursor mass tolerance threshold was set at $10 \mathrm{ppm}$ and maximum fragment mass error was $0.02 \mathrm{Da}$. Label-free quantification was performed using MaxQuant. The match between runs was employed, and the significance threshold of the ion score was calculated based on a false discovery rate of $<1 \%$.

For MIB/MS data analysis, MaxQuant normalized LFQ values were imported into Perseus software (1.6.2.3) for quantitation. MIB/MS profiles were processed in Perseus software in the following manner: normalized MIB/MS LFQ ratios were log2 transformed, MIB/MS technical replicates averaged, rows filtered for minimum valid kinases measured ( $n=>3$ kinases) and normalized by Z-score. Principal component analysis and hierarchical clustering (Euclidean) of kinase log2 LFQ z-scores was then performed to visualize kinome profiles amongst samples. Differences in kinase abundance among sample conditions were determined using a two-sample Student's t-test with the following parameters, (S0 0.1, and Side, Both) using Benjamini-Hochberg FDR 0.05 using Perseus software. The mass spectrometry proteomics files are currently in the process of being deposited to the ProteomeXchange Consortium via the PRIDE partner repository. 


\section{Results}

\section{Inactivation of Pak2 results in decreased incidence and delayed onset and progression of pleural and peritoneal MMs in Nf2-deficient mice}

Locotemporal expression of Cre recombinase by either IT or i.p. injection of adeno-Cre virus was used to induce mesothelial cell-specific homozygous deletions of Nf2, Cdkn2a, with or without excision of Pak2, in homozygous compound CKO mice. Examples of genotyping of $N f 2^{f f f} ; C d k n a^{f / f} ; P a k 2^{+/+}$and $N f 2^{f f f} ; C d k n a^{f / f} ; P a k 2^{f / f}$ mice and immunoblotting demonstrating loss of expression of conditionally knocked out genes in MMs arising after injection of adeno-Cre virus in these animals are depicted in Fig. 1A and 1B, respectively. The IT-injected mice were followed for up to one year, and by the end of the study, 16 of $19 \mathrm{NC} ; P^{w t}$ animals (84\%) developed pleural $\mathrm{MM}$, with a median survival of 26 weeks. In contrast, only 8 of $15(53 \%) N C ; P^{-/-}$mice developed pleural MM, and the median survival was prolonged to 34 weeks. Among animals injected i.p. with adeno-Cre virus, 18 of $22(82 \%) N C ; P^{w t}$ mice developed peritoneal MM (median survival: 24 weeks) versus only 10 of 23 (43\%) NC; $P^{-/}$mice (median survival: 35 weeks). Kaplan-Meier survival curves of IT- and i.p.-injected mice that developed MM are shown in Figure 2A and 2B, respectively. In both the IT and the i.p. studies, the incidence of MM was much lower in NC; $P^{-/-}$ mice than in the $N C ; P^{w t}$ cohort. Moreover, statistical differences in the survival of $N C ; P^{w t}$ versus $N C ; P^{-/}$mice with $\mathrm{MM}$ were highly significant in both IT and i.p. studies. MMs from $N C ; P^{w t}$ and $N C ; P^{-/-}$mice showed similar histopathology, with the vast majority of tumors being sarcomatoid (Supplemental Figure S1), which is consistent with our previous studies of MMs in conditional NC mice (32). 
In vivo bioluminescent imaging confirms that loss of Pak2 delays MM progression in Nf2deficient mice

BLI scanning revealed intense luminescent signals in $N C$; $P^{w t}$ mice beginning at about 6 months, with less signal observed in $N C ; P 2^{+-}$(heterozygous loss of Pak2) littermates (Figure 2C). BLI scanning was repeated with four sets of littermates with different Pak2 genotypes, and in each instance tumor progression, as indicated by diminished intensity of the luminescent signals observed, was consistently delayed in mice with homozygous excision of Pak2.

Knockdown of Pak2 diminishes metastatic colonization of Nf2-deficient MM cells in the lung

MM cells (MM87), which were previously derived from an asbestos exposed $\mathrm{Nf}^{+/-}$ $; C d k n 2 a^{+/-}$mouse, were infected with tet-inducible lentiviruses against Pak2. Two clones that demonstrated marked knockdown of Pak2 (shPak2 85 and shPak2 70 in Figure 3A) were expanded and injected individually into the tail vein of NSG mice. The mice were injected with doxycycline i.p. after 7 days and then every 2 days thereafter; all animals were sacrificed on day 21, and lungs were examined histopathologically for tumor colonization (Figure 3B). H\&E staining revealed that tumor colonization of the lungs by MM87 cells was consistently diminished in the cell clones expressing shRNA against Pak2 versus control MM87 cells infected with lentivirus against GFP (Figure 3C), and the differences were statistically significant $(p<0.05)$.

\section{Loss of Pak2 results in decreased tumor cell migration, cell viability and Erk activity}

We compared cell migration of MM cells from NC; $P^{w t}$ mice versus MM cells from NC; $P^{-/-}$ mice. Twenty-two hours after seeding, the cells were evaluated for migratory ability using a transwell migration assay, as described in the Materials and Methods. As shown in Figure 4A, the $N C ; P^{-/-} \mathrm{MM}$ cell line tested showed markedly less migration than a $N C ; P^{w t} \mathrm{MM}$ cell line. We also found that Erk activity was much lower in $N C ; P^{-/}$MM cells as compared to $N C ; P^{w t} \mathrm{MM}$ cells (Figure 
4B). Furthermore, an MTS assay performed on $N C ; P^{w t} M M$ cells infected with a lentivirus expressing doxycycline-inducible shPak2 revealed a sustained decrease in cell viability beginning at 4 days after starting treatment with doxycycline (Figure 4C, D).

\section{RNA-seq analysis reveals that Pak2 loss in Nf2-null MM cells results in diminished expression of genes involved in oncogenic pathways}

RNA-seq analysis was performed on early passage ( $p$ 3-4) cell lines from 3 peritoneal MMs from $N C ; P^{w t}$ mice and $5 \mathrm{MMs}$ from $N C ; P^{-/-}$mice to identify genes that are differentially expressed due to loss of Pak2, one of the main downstream effectors of Nf2. Most of the differentially expressed genes in MMs from the $\mathrm{NC} ; \mathrm{P}^{-/}$mice were downregulated. Numerous downregulated genes are involved in muscle contraction and cardiac epithelial-mesenchymal transition (EMT) pathways (Supplemental Figure S2), whereas many others are members of Wnt signaling (Wif1, Nkd1, Axin2, Gli1, Gpc3, Notum, Sfrp5, Fzd4/8/9, Porcn, Lrp4, Wnt9b, Sost). Other downregulated genes involved kinase and other cancer-related pathways (Igf2, Fgf9/18, Fgfr3/4, Notch3, Pax7, Pik3r3, Tgfb2) or were stem cell markers (Sox8/11) and integrins (Itga7/8). Fewer upregulated genes were observed in MMs from the $N C ; P^{-/}$mice; these included a Wnt inhibitor gene (Dkk2), two kinase genes (Axl, Styk1), the transcription repressor gene Foxg1, and the dual-specificity phosphatase genes Dusp4 and Dusp5, whose products dephosphorylate MAPK proteins such as ERK. A heatmap of genes differentially expressed in MM cell lines from $N C ; P^{-/-}$mice versus MM lines from $N C ; P^{w t}$ mice is shown in Figure 5, including genes involved in Wnt signaling (Figure 5A) and various other pathways (Figure 5B). Eight cancer-related genes were validated by semiquantitative RT-PCR analysis (Figure 5C).

\section{Assessment of kinome reprogramming in Pak2-null MM cells using MIB/MS technology}

Given that the problem of drug resistance is of paramount importance in aggressive tumors such as $\mathrm{MM}$, we used a technological approach, MIB/MS, that globally measures kinase signaling at 
the proteomic level $(36,37)$ to assess dynamic reprogramming of the kinome in response to genetic inhibition of Pak2 in MM. This technology was used to compare the kinase expression of early passage $\mathrm{MM}$ cells from an $N C ; P^{w t}$ mouse with that of $\mathrm{MM}$ cells from an $N C ; P^{-/}$mouse, with studies performed in triplicate. Kinome activity, principal component analysis (PCA), identities of up- and down-regulated kinases, and heat-map are depicted in Figure 6A-D. The kinome profiling revealed that as compared to $N C ; P^{w t} \mathrm{MM}$ cells, the $N C ; P^{-/-}$MM cells had multiple kinase changes suggestive of an epithelial to mesenchymal transition (EMT). Prominent among the changes associated with loss of Pak2 were upregulation of Pdgfr $\alpha$, Pdgfr $\beta$, Limk1, Fyn, Jak1, Mkk6, and Slug as well as down regulation of Met and Ddr1. Immunoblot confirmation of expression changes in selected kinases is shown in Figure 6E and Figure 7.

\section{Discussion}

Losses of NF2 and CDKN2A are thought to play a critical role in MM pathogenesis. In fact, in human peritoneal MM, homozygous deletions in CDKN2A and hemizygous loss of NF2 as detected by fluorescence in situ hybridization has been reported to confer a poor clinical outcome, whereas loss of BAP1 was not associated with clinical outcome (38). In conditional knockout mice, $N f 2^{f / f}$ mice and $C d k n 2 a^{f / f}$ mice injected IT with adeno-Cre virus resulted in few pleural MMs,

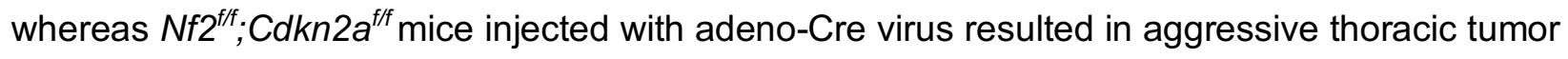
growth $(27,32)$. In this study, $N C ; P^{-/}$mice, with loss of only a single Group I Pak gene, was sufficient to significantly decrease the incidence and delay the onset and progression of both pleural and peritoneal MMs when compared to that of $N C ; P^{w t}$ mice.

Loss of NF2 results in the direct activation of Group I Paks (20) Group I PAKs are frequently activated in human MM tumors, and genetic or pharmacologic inhibition of PAKs is sufficient to inhibit MM cell proliferation and survival (26). PAK1 is frequently overexpressed in 
human breast, ovarian, bladder and brain cancers, often secondary to amplification of its 11q13.514 chromosomal locus (39). Moreover, breast and bladder carcinoma cells bearing such amplification were shown to be highly sensitive to PAK inhibition by small molecule inhibitors or RNAi, suggesting that these cancer cells are "addicted" to PAK1 overexpression. The role of PAK2 in human neoplasia is less well studied, but it has been linked to a variety of human cancers (23). The pathways that mediate the oncogenic effects of PAK overexpression are not fully known, but include activation of the Erk pathway (via phosphorylation of Raf and Mek), inactivation of NF2/Merlin, stabilization of $\beta$-catenin, and possibly by scaffolding interactions that link Pdk1 with Akt (23). Pak1 has been shown to regulate cell motility in mammalian fibroblasts (40), and we show here that loss of Pak2 in Nf2-deficient MM cells similarly results in decreased MM cell migration. Loss of PAK function is associated with decreased cell proliferation and migration, with concomitant loss of activity of these signaling pathways (41). Consistent with these data, our findings demonstrate that loss of Pak2 results in diminished MM cell motility, decreased expression of Akt pathway-related genes, and reduced Erk activity.

Our RNA-seq analysis revealed that loss of Pak2 counteracts some aspects of Nf2 lossof-function in MM cells by downregulating the expression of multiple genes involved in oncogenic pathways, particularly genes encoding proteins involved in Wnt signaling, such as Wnt9b and several Fzd (frizzled class receptor) genes as well as in Akt signaling, e.g., lgf2, Fgf, Fgfr, and Pik3r3. Among the comparatively few upregulated genes observed in $\mathrm{MM}$ cells from $\mathrm{NC} ; \mathrm{P}^{-/-}$mice, Dkk2 is a Wnt inhibitor gene, Foxg1 encodes an oncoprotein that inhibits the transcriptional activation of the proapoptotic protein FoxO1 (42), and Dusp4/5 encode dual-specificity phosphatases that dephosphorylate MAPK proteins such as ERK. Consistent with the latter, we found that Erk activity was markedly diminished in NC; $P^{-/-}$MM cells compared to NC; $P^{w t} \mathrm{MM}$ cells (Figure 4B). One other upregulated gene in Pak2-null MM cells, Styk1, encodes a serine threonine tyrosine kinase 1 that has been correlated with poor prognosis, tumor invasion, and metastasis of non-small cell lung cancer (NSCLC) patients (43). STYK1 overexpression also promoted 
proliferation, migration, and invasion of NSCLC cells and induced EMT by E-cadherin downregulation and Snail upregulation. Similarly, E-cadherin expression was greatly downregulated in the $N C ; P^{-1-}$ MM cells used for our MIB/MS kinome profiling study, whereas Ecadherin expression was abundant in $N C ; P^{w t} \mathrm{MM}$ cells (Fig. 5E). Collectively, these data point to a positive role for group I Paks in tumorigenesis, mediated by several central signaling pathways. Our findings further suggest that inhibitors of Pak might be useful in switching off such signaling pathways. The data presented here help establish a framework for understanding MM adaptation and permit the design of rational combinations of targeted agents, as clinical or near-clinical inhibitors for many protein kinases already exist.

The RNA-seq profiling presented here also demonstrated that numerous genes that are downregulated in NC; $P^{--}$MM cells are involved in muscle contraction and cardiac epithelial to mesenchymal transition (EMT) pathways. These data are consistent with previous work showing a significant role for Group I Paks in myoblast and cardiac muscle function. For example, the Rac1-Pak2 pathway has been shown to be indispensable for zebrafish heart regeneration (44). Furthermore, Pak2 has been identified as a primary mediator of ER stress in chronic myocardial injury, and melatonin-mediated Pak2 activation has been shown to decrease cardiomyocyte death by repressing hypoxia reoxygenation injury-induced endoplasmic reticulum-related stress (45). In addition, Group I Paks have been shown to promote skeletal myoblast differentiation during postnatal development and regeneration in mice, and adult mice conditionally lacking both Pak1 and Pak2 in the skeletal muscle lineage developed an age-related myopathy, with muscles exhibiting centrally-nucleated myofibers, fibrosis, and signs of degeneration (46). As in the RNAseq studies, kinome profiling assayed by MIB/MS technology also uncovered kinase changes indicative of EMT in $N C ; P 2^{-/-} \mathrm{MM}$ cells, including upregulation of Pdgfra, Pdgfrb, Fyn, and the EMT transcription regulator Slug. Recent work has clarified the EMT cell plasticity program as a set of dynamic transitional states between the epithelial and mesenchymal phenotypes, with EMT and its intermediary states serving as critical drivers of organ fibrosis and tumor progression (47). 
Together, these findings suggest that Nf2-deficient MM cells with loss of Pak2 ultimately adapt by reprogramming their kinome to bypass the need for Pak activity. While Paks are vital to oncogenic signaling in NF2-null MM cells, targeted genetic inactivation of Pak2 in Nf2-null MM cells resulted in downregulated expression of genes involved in oncogenic pathways. Eventually, however, MMs develop in $N C ; P^{-/-}$mice apparently by compensatory activation of oncogenic pathways involving other kinases such as Styk1, Pdgfra/ß, Axl, Jak/Stat, and Fyn. Such information can inform the design of rational combination therapies for MM using molecularly targeted inhibitors. Germane to this, one kinase gene $(A x I)$ that was upregulated in MMs from $N C ; P^{-/-}$mice is noteworthy because there are promising new inhibitors for Axl that might be used in combination with a Pak inhibitor (48). The identification of such secondary pathways that could be co-targeted to prevent resistance to anti-Pak drugs, thus sets the stage for future preclinical studies with novel therapeutics.

\section{Acknowledgments}

This work was supported by NCl grants CA148805 (to J.R. Testa and J. Chernoff) and CA06927 (to FCCC) and an appropriation from the Commonwealth of Pennsylvania to FCCC. Other support was provided by the Local \#14 Mesothelioma Fund of the International Association of Heat and Frost Insulators and Allied Workers. The following FCCC core services assisted this project: Laboratory Animal, Transgenic Mouse, Genomics, Cell Culture, DNA Sequencing, Histopathology, and Biostatistics and Bioinformatics Facilities.

\section{References}

1. Britton M. The epidemiology of mesothelioma. Semin Oncol 2002;29:18-25. 
2. Cheng JQ, Jhanwar SC, Klein WM, Bell DW, Lee W-C, Altomare DA, et al. $p 16$ alterations and deletion mapping of 9p21-p22 in malignant mesothelioma. Cancer Res 1994;54:554751.

3. Sekido Y, Pass HI, Bader S, Mew DJY, Christman MF, Gazdar AF, et al. Neurofibromatosis type 2 (NF2) gene is somatically mutated in mesothelioma but not in lung cancer. Cancer Res 1995;55:1227-31.

4. Bianchi AB, Mitsunaga S-I, Cheng JQ, Klein WM, Jhanwar SC, Seizinger B, et al. High frequency of inactivating mutations in the neurofibromatosis type 2 gene (NF2) in primary malignant mesotheliomas. Proc Natl Acad Sci U S A 1995;92:10854-8.

5. Cheng JQ, Lee WC, Klein MA, Cheng GZ, Jhanwar SC, Testa JR. Frequent mutations of NF2 and allelic loss from chromosome band 22q12 in malignant mesothelioma: evidence for a two-hit mechanism of NF2 inactivation. Genes Chromosomes Cancer 1999;24:23842.

6. Altomare DA, Vaslet CA, Skele KL, De Rienzo A, Devarajan K, Jhanwar SC, et al. A mouse model recapitulating molecular features of human mesothelioma. Cancer Res 2005;65:8090-5.

7. Bott M, Brevet M, Taylor BS, Shimizu S, Ito T, Wang L, et al. The nuclear deubiquitinase BAP1 is commonly inactivated by somatic mutations and 3p21.1 losses in malignant pleural mesothelioma. Nat Genet 2011;43:668-72.

8. Testa JR, Cheung M, Pei J, Below JE, Tan Y, Sementino E, et al. Germline BAP1 mutations predispose to malignant mesothelioma. Nat Genet 2011;43:1022-5.

9. Nasu M, Emi M, Pastorino S, Tanji M, Powers A, Luk H, et al. High incidence of somatic BAP1 alterations in sporadic malignant mesothelioma. J Thorac Oncol 2015;10:565-76.

10. Hmeljak J, Sanchez-Vega F, Hoadley KA, Shih J, Stewart C, Heiman D, et al. Integrative molecular characterization of malignant pleural mesothelioma. Cancer Discov 2018;8:1548-65.

11. Fleury-Feith J, Lecomte C, Renier A, Matrat M, Kheuang L, Abramowski V, et al. Hemizygosity of $\mathrm{Nf} 2$ is associated with increased susceptibility to asbestos-induced peritoneal tumours. Oncogene 2003;22:3799-805.

12. Zhou D, Conrad C, Xia F, Park JS, Payer B, Yin Y, et al. Mst1 and Mst2 maintain hepatocyte quiescence and suppress hepatocellular carcinoma development through inactivation of the Yap1 oncogene. Cancer Cell 2009;16:425-38. 
13. Murakami H, Mizuno T, Taniguchi T, Fujii M, Ishiguro F, Fukui T, et al. LATS2 is a tumor suppressor gene of malignant mesothelioma. Cancer Res 2011;71:873-83.

14. Mizuno T, Murakami H, Fujii M, Ishiguro F, Tanaka I, Kondo Y, et al. YAP induces malignant mesothelioma cell proliferation by upregulating transcription of cell cyclepromoting genes. Oncogene 2012;31:5117-22.

15. Li W, Cooper J, Zhou L, Yang C, Erdjument-Bromage H, Zagzag D, et al. Merlin/NF2 lossdriven tumorigenesis linked to CRL4(DCAF1)-mediated inhibition of the hippo pathway kinases Lats1 and 2 in the nucleus. Cancer Cell 2014;26:48-60.

16. Shaw RJ, McClatchey Al, Jacks T. Localization and functional domains of the neurofibromatosis type II tumor suppressor, merlin. Cell Growth Diff 1998;9:287-96.

17. Morrison H, Sherman LS, Legg J, Banine F, Isacke C, Haipek CA, et al. The NF2 tumor suppressor gene product, merlin, mediates contact inhibition of growth through interactions with CD44. Genes Dev 2001;15:968-80.

18. Xiao GH, Beeser A, Chernoff J, Testa JR. p21-activated kinase links Rac/Cdc42 signaling to merlin. J Biol Chem 2002;277:883-6.

19. Kissil JL, Johnson KC, Eckman MS, Jacks T. Merlin phosphorylation by p21-activated kinase 2 and effects of phosphorylation on merlin localization. J Biol Chem 2002;277:10394-9.

20. Kissil JL, Wilker EW, Johnson KC, Eckman MS, Yaffe MB, Jacks T. Merlin, the product of the Nf2 tumor suppressor gene, is an inhibitor of the p21-activated kinase, Pak1. Mol Cell 2003;12:841-9.

21. Rong R, Surace El, Haipek CA, Gutmann DH, Ye K. Serine 518 phosphorylation modulates merlin intramolecular association and binding to critical effectors important for NF2 growth suppression. Oncogene 2004;23:8447-54.

22. Thurneysen C, Opitz I, Kurtz S, Weder W, Stahel RA, Felley-Bosco E. Functional inactivation of NF2/merlin in human mesothelioma. Lung Cancer 2009;64:140-7.

23. Radu M, Semenova G, Kosoff R, Chernoff J. PAK signalling during the development and progression of cancer. Nat Rev Cancer 2014;14:13-25.

24. Hofmann C, Shepelev M, Chernoff J. The genetics of Pak. J Cell Sci 2004;117:4343-54.

25. Bokoch GM. Biology of the p21-activated kinases. Ann Rev Biochem 2003;72:743-81. 
26. Menges CW, Sementino E, Talarchek J, Xu J, Chernoff J, Peterson JR, et al. Group I p21activated kinases (PAKs) promote tumor cell proliferation and survival through the AKT1 and Raf-MAPK pathways. Mol Cancer Res 2012;10:1178-88.

27. Jongsma J, van Montfort E, Vooijs M, Zevenhoven J, Krimpenfort P, van der Valk M, et al. A conditional mouse model for malignant mesothelioma. Cancer Cell 2008;12:261-71.

28. Radu M, Lyle K, Hoeflich KP, Villamar-Cruz O, Koeppen H, Chernoff J. p21-activated kinase 2 regulates endothelial development and function through the Bmk1/Erk5 pathway. Mole Cell Biol 2015;35:3990-4005.

29. Connolly DC, Hensley $\mathrm{HH}$. Xenograft and transgenic mouse models of epithelial ovarian cancer and non-invasive imaging modalities to monitor ovarian tumor growth in situ: applications in evaluating novel therapeutic agents. Curr Protoc Pharmacol 2009;45:14.2.1-2.6.

30. Wiederschain D, Wee S, Chen L, Loo A, Yang G, Huang A, et al. Single-vector inducible lentiviral RNAi system for oncology target validation. Cell Cycle 2009;8:498-504.

31. Menges CW, Kadariya Y, Altomare D, Talarchek J, Neumann-Domer E, Wu Y, et al. Tumor suppressor alterations cooperate to drive aggressive mesotheliomas with enriched cancer stem cells via a p53-miR-34a-c-Met axis. Cancer Res 2014;74:1261-71.

32. Kukuyan AM, Sementino E, Kadariya Y, Menges CW, Cheung M, Tan Y, et al. Inactivation of Bap1 cooperates with losses of Nf2 and Cdkn2a to drive the development of pleural malignant mesothelioma in conditional mouse models. Cancer Res 2019;79:4113-23.

33. Love MI, Huber W, Anders S. Moderated estimation of fold change and dispersion for RNA-seq data with DESeq2. Genome Biol 2014;15:550.

34. Durinck S, Spellman PT, Birney E, Huber W. Mapping identifiers for the integration of genomic datasets with the R/Bioconductor package biomaRt. Nat Protoc 2009;4:1184-91.

35. Subramanian A, Tamayo P, Mootha VK, Mukherjee S, Ebert BL, Gillette MA, et al. Gene set enrichment analysis: a knowledge-based approach for interpreting genome-wide expression profiles. Proc Natl Acad Sci U S A 2005;102:15545-50.

36. Kurimchak AM, Shelton C, Duncan KE, Johnson KJ, Brown J, O'Brien S, et al. Resistance to $B E T$ bromodomain inhibitors is mediated by kinome reprogramming in ovarian cancer. Cell Rep 2016;16:1273-86. 
37. Duncan JS, Whittle MC, Nakamura K, Abell AN, Midland AA, Zawistowski JS, et al. Dynamic reprogramming of the kinome in response to targeted MEK inhibition in triplenegative breast cancer. Cell 2012;149:307-21.

38. Singhi AD, Krasinskas AM, Choudry HA, Bartlett DL, Pingpank JF, Zeh HJ, et al. The prognostic significance of $B A P 1, N F 2$, and $C D K N 2 A$ in malignant peritoneal mesothelioma. Mod Pathol 2016;29:14-24.

39. Dummler B, Ohshiro K, Kumar R, Field J. Pak protein kinases and their role in cancer. Cancer Metas Rev 2009;28:51-63.

40. Sells MA, Boyd JT, Chernoff J. p21-activated kinase 1 (Pak1) regulates cell motility in mammalian fibroblasts. J Cell Biol 1999;145:837-49.

41. Allen JD, Jaffer ZM, Park SJ, Burgin S, Hofmann C, Sells MA, et al. p21-activated kinase regulates mast cell degranulation via effects on calcium mobilization and cytoskeletal dynamics. Blood 2009;113:2695-705.

42. Aoki $\mathrm{M}$, Jiang $\mathrm{H}$, Vogt PK. Proteasomal degradation of the FoxO1 transcriptional regulator in cells transformed by the P3k and Akt oncoproteins. Proc Natl Acad Sci U S A 2004;101:13613-7.

43. Ma Z, Liu D, Li W, Di S, Zhang Z, Zhang J, et al. STYK1 promotes tumor growth and metastasis by reducing SPINT2/HAI-2 expression in non-small cell lung cancer. Cell Death Dis 2019;10:435.

44. Peng X, He Q, Li G, Ma J, Zhong TP. Rac1-PAK2 pathway Is essential for zebrafish heart regeneration. Biochem Biophys Res Commun 2016;472:637-42.

45. Wang S, Bian W, Zhen J, Zhao L, Chen W. Melatonin-mediated Pak2 activation reduces cardiomyocyte death through suppressing hypoxia reoxygenation injury-induced endoplasmic reticulum stress. J Cardiovasc Pharmacol 2019;74:20-9.

46. Joseph GA, Hung M, Goel AJ, Hong M, Rieder MK, Beckmann ND, et al. Late-onset megaconial myopathy in mice lacking group I Paks. Skelet Muscle 2019;9:5.

47. Nieto MA, Huang RY-J, Jackson RA, Thiery JP. EMT: 2016. Cell 2916;166:21-45.

48. Sun ZG, Liu JH, Zhang JM, Qian Y. Research progress of Axl inhibitors. Curr Top Med Chem 2019;19:1338-49.

49. Huang W-C, Tung S-L, Chen YL, Chen P-M, Chu P-Y. IFI44L is a novel tumor suppressor in human hepatocellular carcinoma affecting cancer stemness, metastasis, and drug resistance via regulating met/Src signaling pathway. BMC Cancer 2018;18:609. 
bioRxiv preprint doi: https://doi.org/10.1101/2020.06.30.181453; this version posted July 1, 2020. The copyright holder for this preprint (which was not certified by peer review) is the author/funder. All rights reserved. No reuse allowed without permission.

50. Huang DW, Sherman BT, Tan Q, Kir J, Liu D, Bryant D, et al. DAVID Bioinformatics Resources: expanded annotation database and novel algorithms to better extract biology from large gene lists. Nucleic Acids Res 2007;35:W169-75. 


\section{Figure Legends}

Figure 1. Genotyping of $N f 2^{f / f} ; C d k n a^{f / f} ; P a k 2^{+/+}$and $N f 2^{f / f} ; C d k n a^{f / f} ; P a k 2^{f / f}$ mice injected intrathoracically (IT) or intraperitoneally (i.p.) with adeno-Cre virus and immunoblotting demonstrating loss of expression of conditionally knocked out genes in malignant mesotheliomas (MMs) from these mice. (A) Genotyping of tail DNA from four representative $N f 2^{f / f} ; C d k n a^{f / f} ; P a k 2^{+/+}$ mice and four $N f 2^{f / f} ; C d k n a^{f / f} ; P a k 2^{f / f}$ mice that developed peritoneal MM after i.p. injection of adenoCre virus. PCR controls for floxed and wild type alleles of Cdkn2a, Nf2 and Pak2 were from tail DNA of control heterozygous and homozygous mice conditional knockout mice. (B) Immunoblotting of early passage cell lines derived from peritoneal MMs of $N C ; P^{-/-}$and $N C ; P^{w t}$ mice. NMC, normal (mouse) mesothelial cells.

Figure 2. MM progression, incidence and Kaplan-Meier survival curves of cohorts of conditional $N f 2^{f / f} ; C d k n a^{f / f} ; P a k 2^{+/+}$and $N f 2^{f f f} ; C d k n a^{f / f} ; P a k 2^{f / f}$ mice injected intrathoracically (IT) or intraperitoneally (i.p.) with adeno-Cre virus. (A) MM incidence and survival of mice injected IT with virus and succumbing to MM. (B) MM incidence and survival in mice injected i.p. The difference in the incidence of $\mathrm{MM}$ between $P a k 2^{\text {wt }}$ and $P a k 2^{-/-}$mice injected i.p. was highly significant $(p$-value $<0.01)$, while the $p$-value for the difference in the incidence of MM between Pak2 $^{\text {wt }}$ and Pak2 ${ }^{-/-}$mice injected IT was $<0.06$ (Fisher's exact test). (C) Bioluminescent imaging reveals delayed MM tumor progression in Nf2-null mice following excision of one or both alleles of Pak2. ${ }^{f f} L u c R ; N f 2^{f / f} ; C d k n 2 a^{f / f}$ mice were crossed to Pak2/ff mice to generate offspring having wild type $\left({ }^{+/+}\right)$Pak2 or with one or both floxed $\left({ }^{+/ f}\right.$ or ${ }^{f / f}$, respectively) Pak2 alleles. Mice were injected intrathoracically (IT) with adeno-Cre virus to excise floxed alleles of thoracic mesothelial lining cells. Infection with adeno-Cre virus also removes a floxed polyadenylation sequence before the ORF of a luciferase reporter transgene ( $L u c R)$. The latter permits luciferase expression to monitor 
tumor progression, using D-luciferin as a substrate and bioluminescent imaging with an IVIS Imaging System. Shown is bioluminescent imaging on two sets of ${ }^{f f} L u c R ; N C$ littermates with three different Pak2 genotypes. The mice were injected with D-luciferin substrate 6 months (left panel) or 7 months (right) after IT injection of adeno-Cre virus; mice with excision of Pak2 show delayed tumor progression as indicated by reduced intensity of luminescent signals.

Figure 3. Knockdown of Pak2 diminishes metastatic colonization of Nf2-deficient MM cells in the lung. Cell line MM87, which was derived from asbestos-induced MM from a $N f 2^{+/-} ; C d k n 2 a^{+/-}$ mouse, were infected with tet-inducible lentiviruses against Pak2. (A) Immunoblot demonstrating expression of Pak2 after knockdown with shRNA. Two clones with robust knockdown of Pak2 (shPak2 85 and shPak2 70) and one clone infected with lentivirus against GFP, used as a control, were selected for tail vein injections into NSG mice. (B) MM clones were each injected into the tail vein of three different NGS mice, followed by injection with doxycycline 7 days later and every 2 days thereafter; all animals were sacrificed on day 21, and lungs were collected for histopathological assessment of tumor burden. (C) H\&E staining illustrating representative tumor colonization (darkly stained areas) of lungs by MM87 cells expressing shGFP, shPak2 85 , or shPak2 70. Bar graph of percent of lung consisting of tumor is shown in the panel at the lower right.

Figure 4. Loss of Pak2 results in decreased tumor cell migration, cell viability and Erk activity. (A) In vitro migration of $\mathrm{MM}$ cells from $N C ; P^{w t}$ mice and $N C ; P^{-/-}$mice was measured using a transwell assay. Twenty-two hours after seeding, the MM cells were evaluated for migratory ability as described in the Materials and Methods, with cells seeded in triplicate wells. Note that $N C ; P^{-/-}$ cells tested show markedly less migration than $N C$; $P^{w t}$ cells. (B) Immunoblotting illustrating decreased Erk activity in NC; $P^{-/-}$MM cells than in NC; $P^{w t}$ MM cells. (C) Immunoblot demonstrating knockdown of Pak2 in $N C ; P^{w t} \mathrm{MM}$ cells infected with lentivirus expressing either of two 
doxycycline-inducible shPak2 (\#70 and \#85) after treatment with doxycycline for $72 \mathrm{~h}$. (D) MTS assay performed on $N C ; P^{w t} \mathrm{MM}$ cells infected with lentivirus expressing doxycycline-inducible shPak2 showing sustained decrease in cell viability beginning at 4 days after starting treatment with doxycycline. Lentivirus expressing shGFP was used as a control.

Figure 5. Heatmaps showing expression patterns of genes in Pak2 ${ }^{-/}$and Pak2 $2^{\text {wt }}$ tumors. Heatmaps depict differentially expressed genes observed in peritoneal MMs tumors from $3 N C ; P^{w t}$ mice versus 5 peritoneal MMs from $N C ; P^{--}$mice. (A) Genes involved in Wnt signaling pathway regulation. (B) Genes that involve multiple pathways including Akt and Notch signaling, cardiac EMT pathway, cell cycling, stem cell pathways, and integrins. (C) Validation of several differentially expressed genes by semi-quantitative RT-PCR analysis. Down-regulated genes in $N C ; P^{-/-}$MM cells tested include two involved in Wnt signaling, Fzd9 and Axin2, several involved in Akt signaling, Igf2, Fgf9 and Fgfr4, and a novel tumor suppressor gene, Ifl44L, which has been implicated in cancer stemness, metastasis, and drug resistance via regulating met/Src signaling (49). Controls include MM marker genes MsIn (mesothelin) and Wt1. Note floxed Pak2 allele only in $\mathrm{NC} ; \mathrm{P}^{-/} \mathrm{MMs}$, with weak wild type (WT) allele due to contaminating stroma in these tumor samples. NMC, normal mesothelial cells.

Figure 6. Kinome profiling of $N C ; P^{-/-} \mathrm{MM}$ cells and $N C ; P^{w t} \mathrm{MM}$ cells. Early passage MM cell cultures were derived from tumors observed in $N f 2^{f / f} ; C d k n 2 a^{f / f}$ and $N f 2^{f / f} ; C d k n 2 a^{f / f} ; P a k 2^{f / f}$ mice injected IT with adeno-Cre virus. (A) Kinome activity as measure by MIBs. (B) PCA analysis, showing differential kinome profiles. (C) Volcano plot depicts kinases exhibiting induced or repressed MIB binding in cells with knockout of Pak2. (D) Heat-map depicts statistical changes in kinase levels between $N C ; P^{-/}$and $N C ; P^{w t} \mathrm{MM}$ cells. (E) Immunoblot confirmation of expression changes in selected kinases. 
bioRxiv preprint doi: https://doi.org/10.1101/2020.06.30.181453; this version posted July 1, 2020. The copyright holder for this preprint (which was not certified by peer review) is the author/funder. All rights reserved. No reuse allowed without permission.

Figure 7. Expression of various key proteins in a series of $N C ; P^{w t}$ and $N C ; P^{-/-}$cell lines derived from pleural MMs. Loss of Pak2 expression correlates with upregulation of Pdgfr $\alpha$, Pdgfr $\beta$, and phospho-Stat3. NMC, normal mesothelial cells. 


\section{Figures}

Fig. 1

A

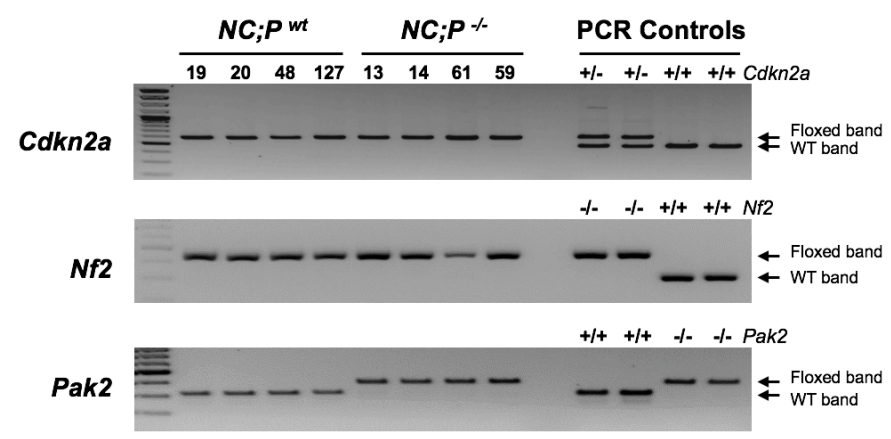

B

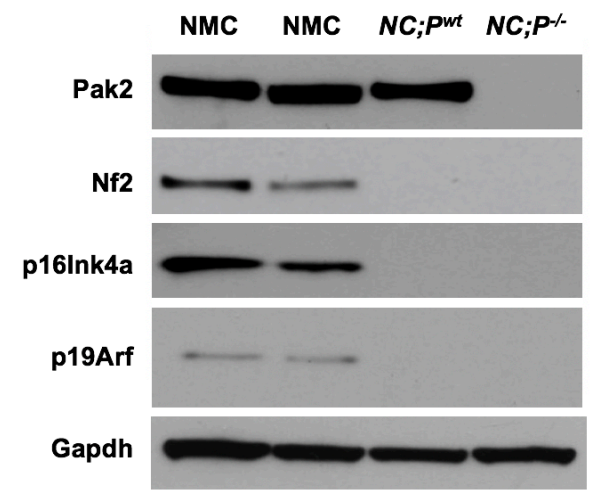


Fig. 2

A

MM incidence and survival after IT injection of adeno-Cre

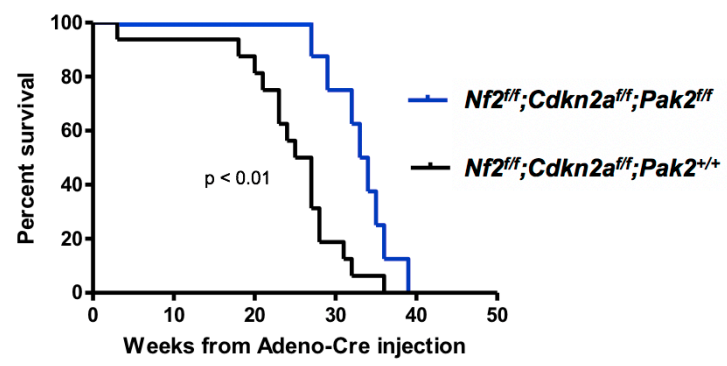

\begin{tabular}{|c|c|c|}
\hline Genotype & $\begin{array}{c}\text { Median survival } \\
\text { of mice with MM }\end{array}$ & $\begin{array}{c}\text { MM incidence } \\
(\%)\end{array}$ \\
\hline$N f 2^{f f f} ; C d k n 2 a^{f f f} ; P a k 2^{+/+}$ & 26 weeks & $16 / 19(84 \%)$ \\
\hline$N f 2^{f f f} ; C d k n 2 a^{f f f} ; P a k 2^{f f f}$ & 34 weeks & $8 / 15(53 \%)$ \\
\hline
\end{tabular}

B

MM incidence and survival after i.p. injection of adeno-Cre

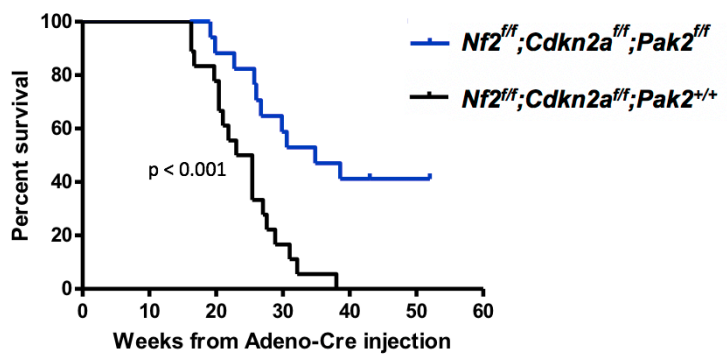

\begin{tabular}{|c|c|c|}
\hline Genotype & $\begin{array}{c}\text { Median survival } \\
\text { of mice with MM }\end{array}$ & $\begin{array}{c}\text { MM incidence } \\
(\%)\end{array}$ \\
\hline$N 2^{f f f} ; C d k n 2 a^{f f f} ; P a k 2^{+/+}$ & 24 weeks & $18 / 22(82 \%)$ \\
\hline$N f 2^{f f f} ; C d k n 2 a^{f f f} ; P a k 2^{f f f}$ & 35 weeks & $10 / 23(43 \%)$ \\
\hline
\end{tabular}

\section{C}
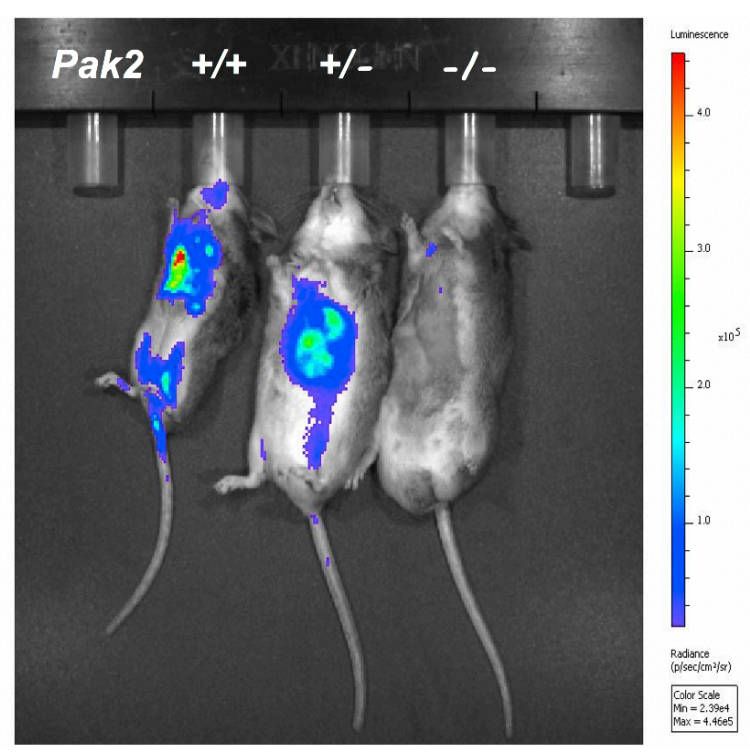

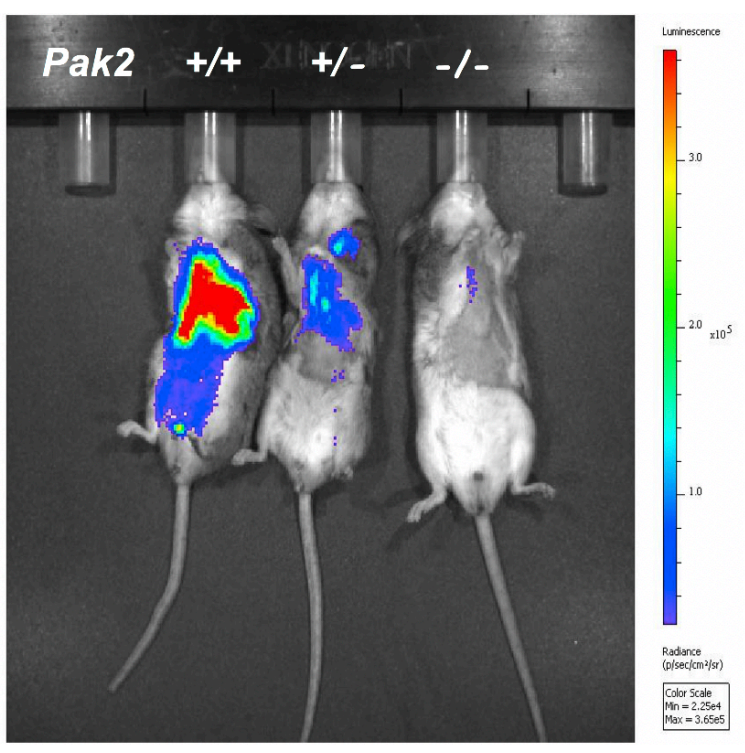


Fig. 3

A

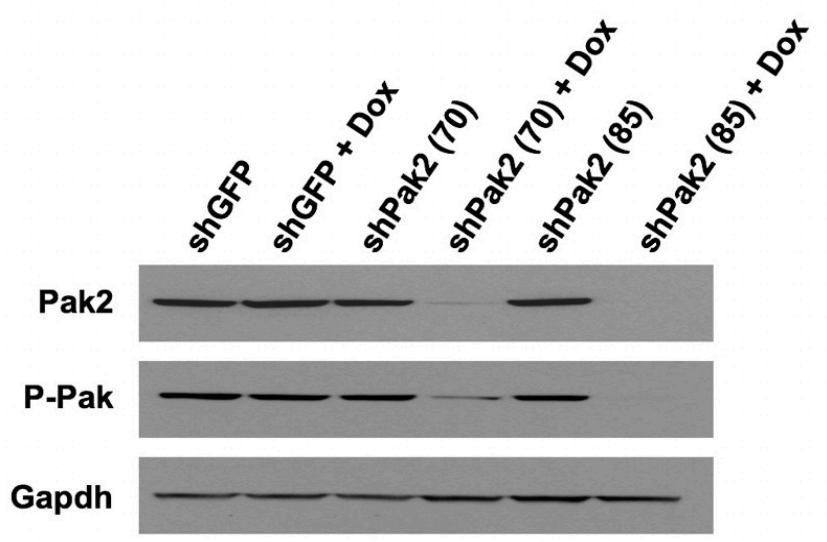

B
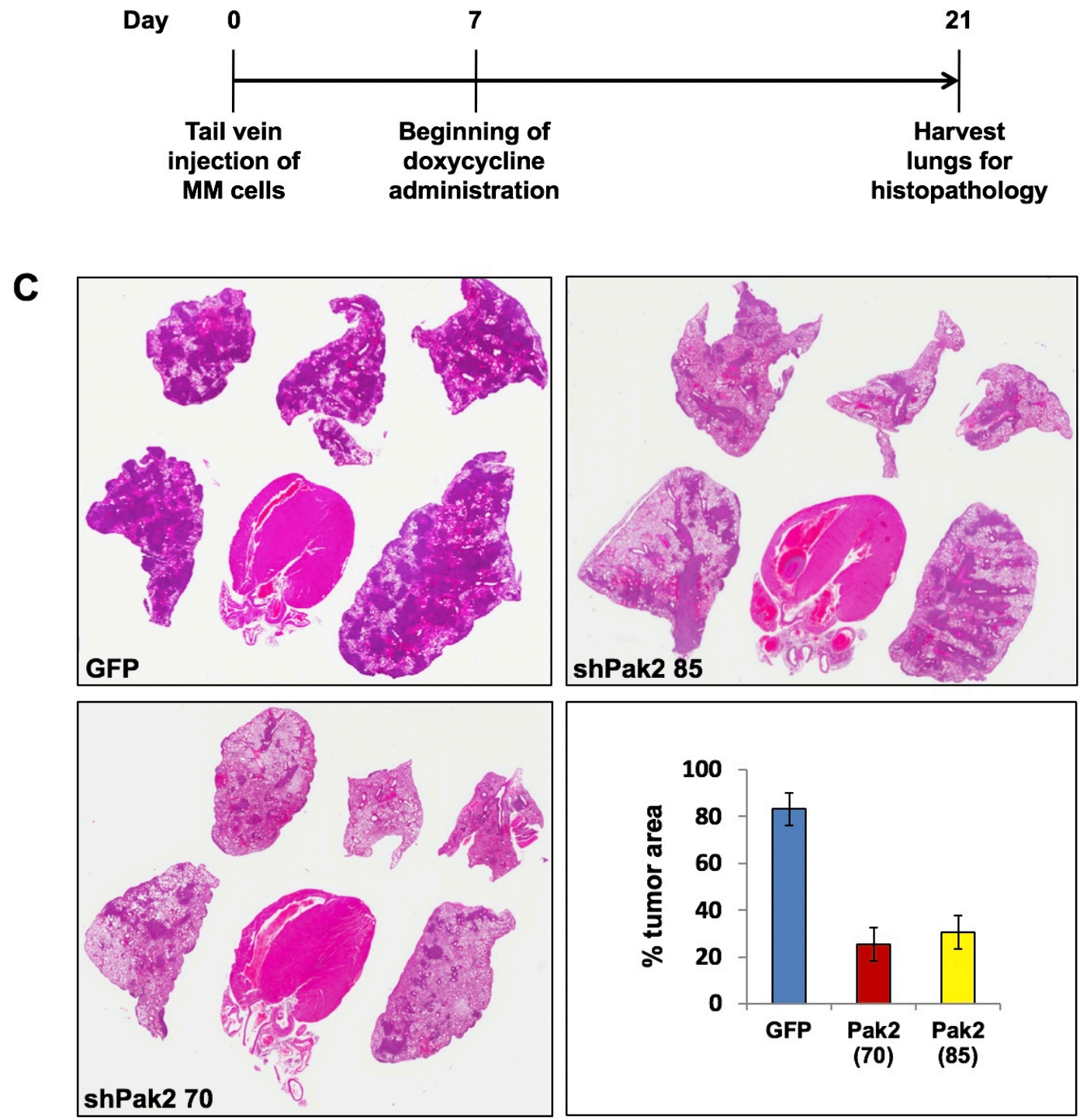
bioRxiv preprint doi: https://doi.org/10.1101/2020.06.30.181453; this version posted July 1, 2020. The copyright holder for this preprint (which was not certified by peer review) is the author/funder. All rights reserved. No reuse allowed without permission.

Fig. 4

A

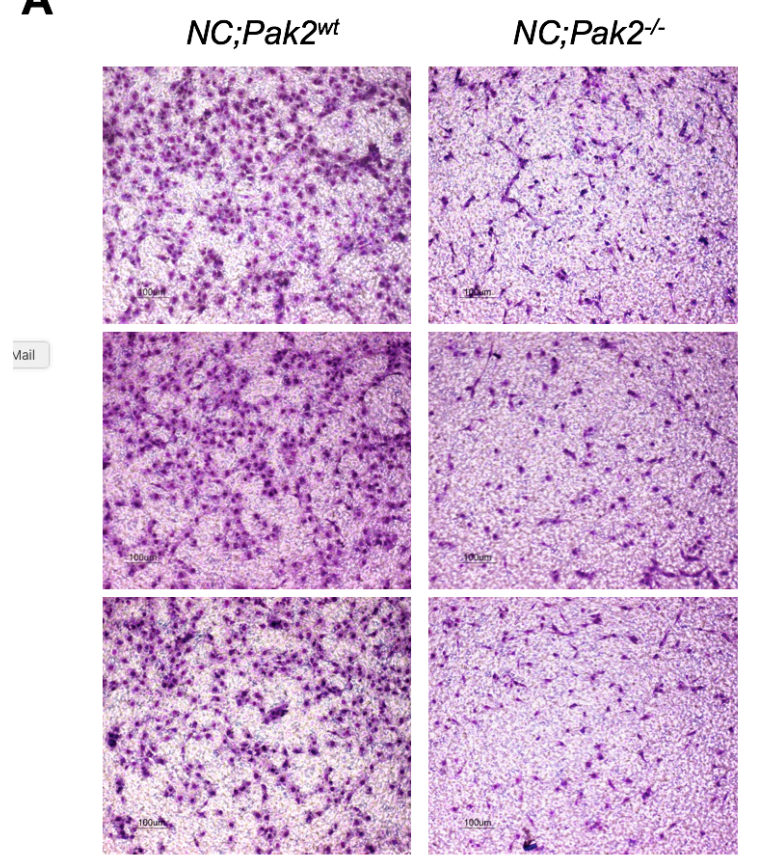

B

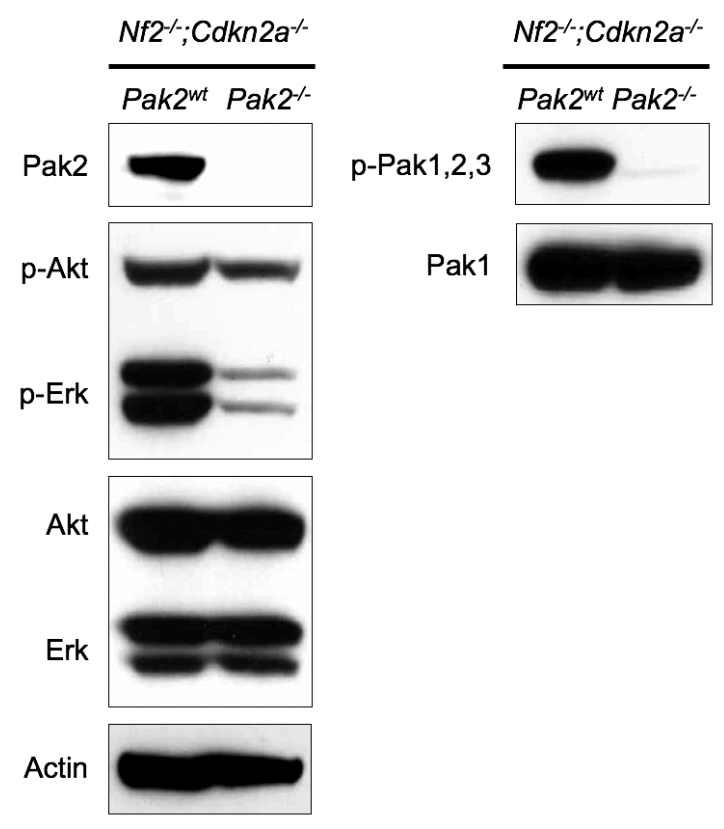

D

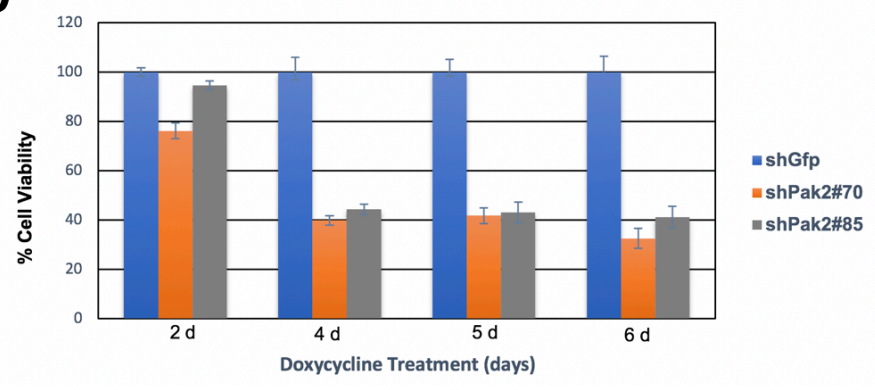


Fig. 5

A

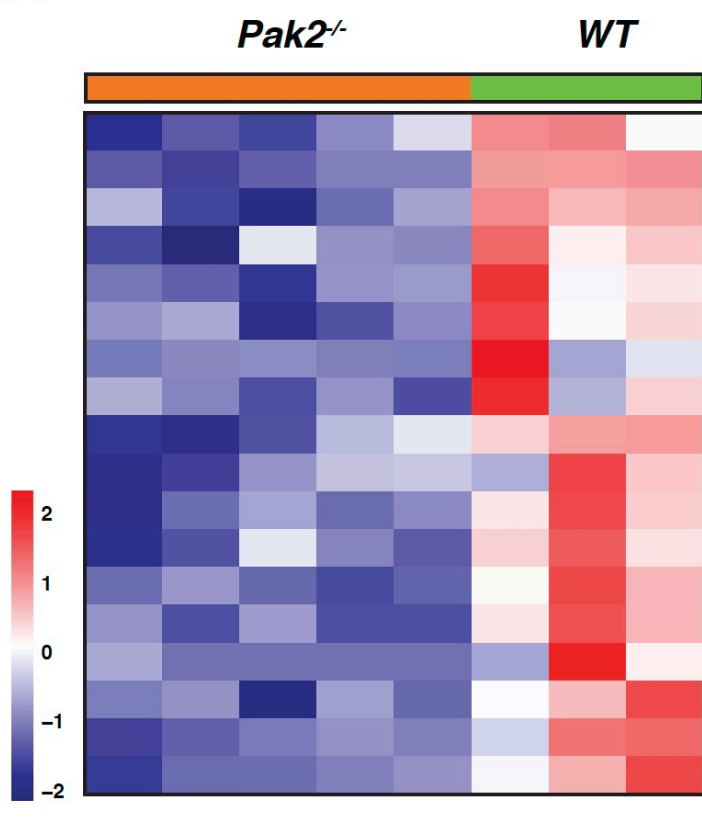

B

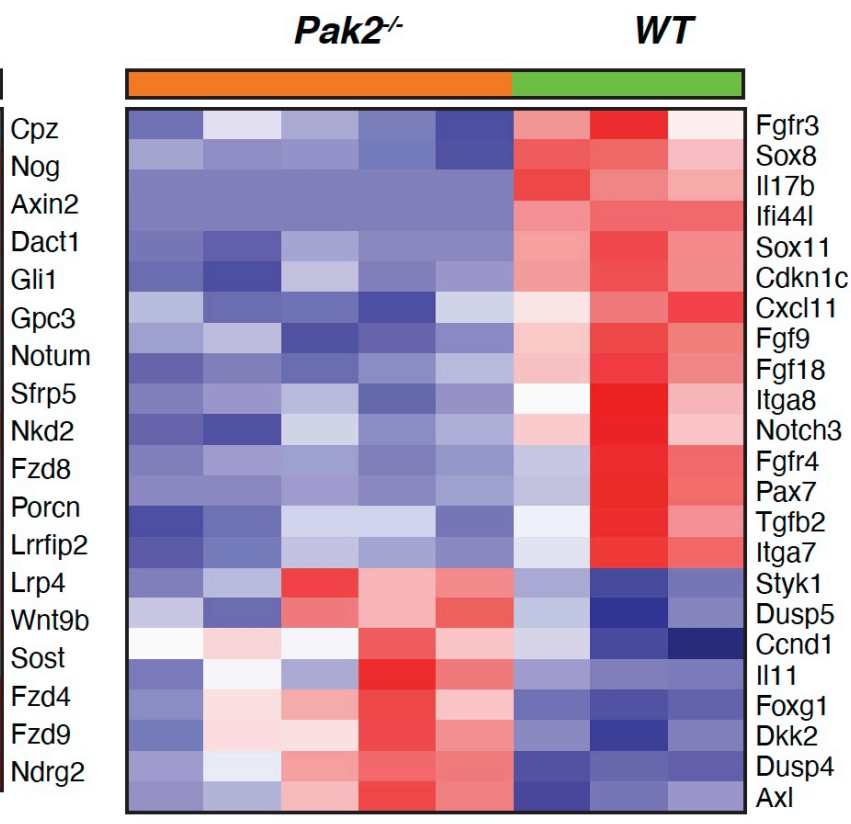

C
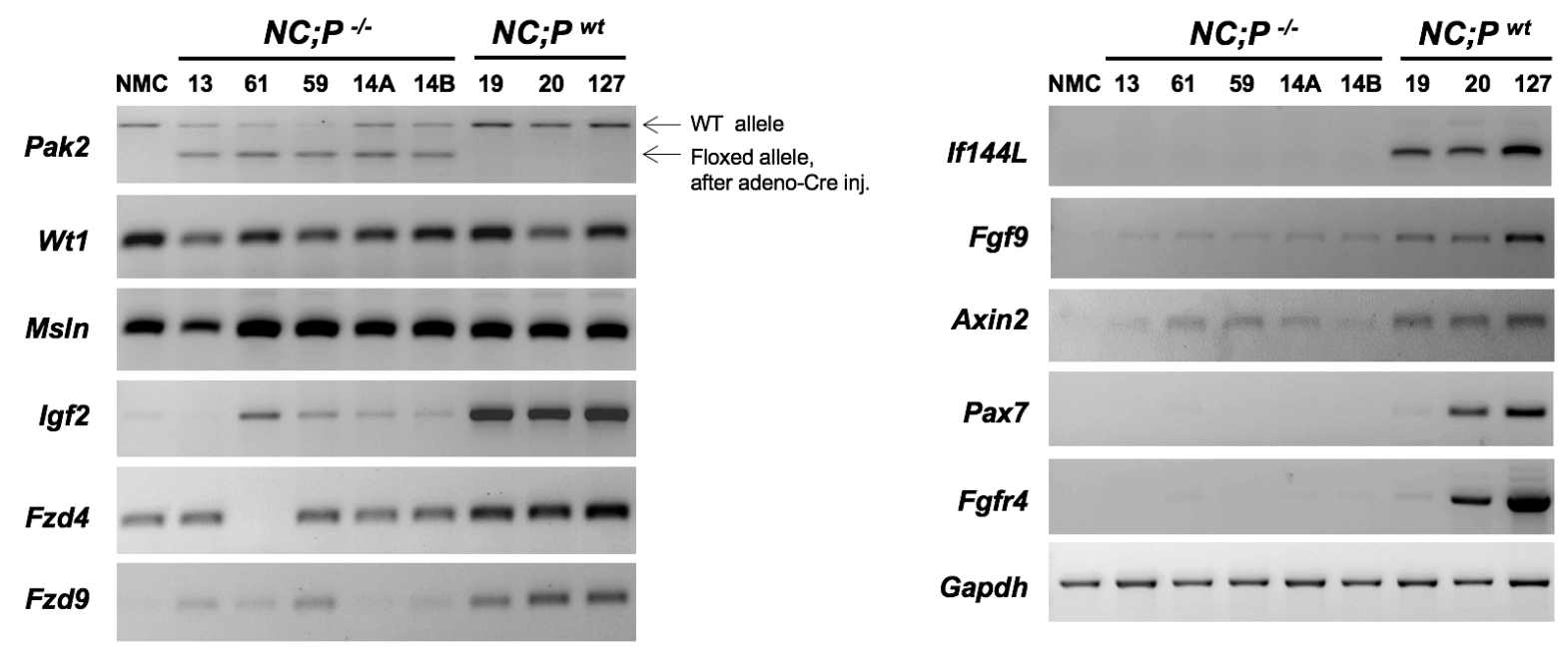
Fig. 6

A

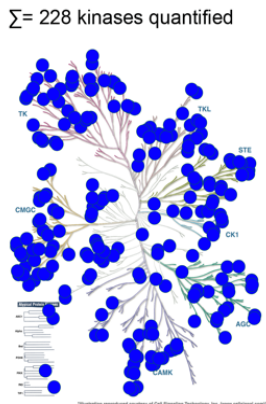

B

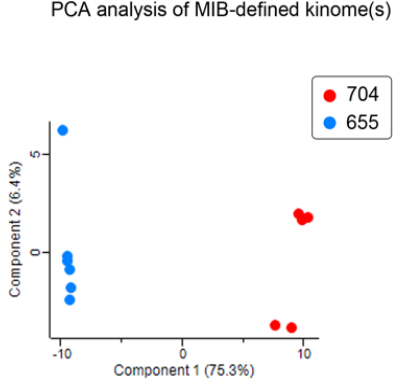

C

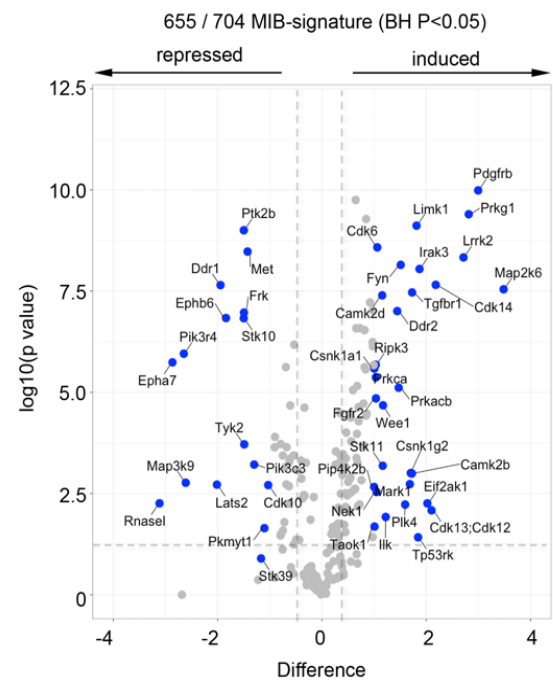

E
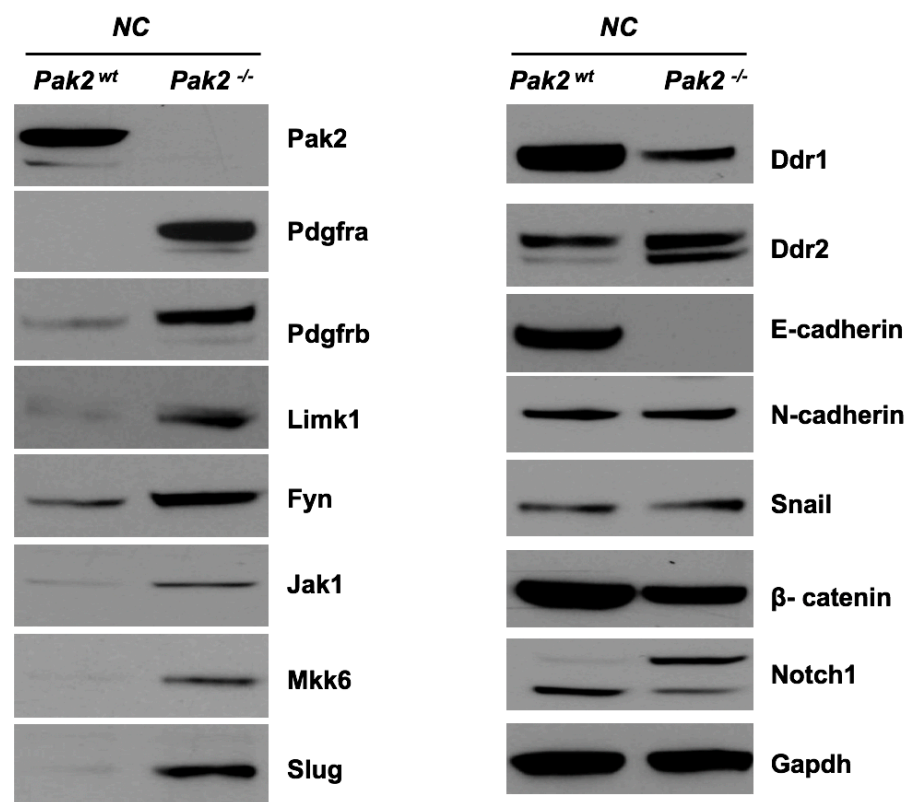

D
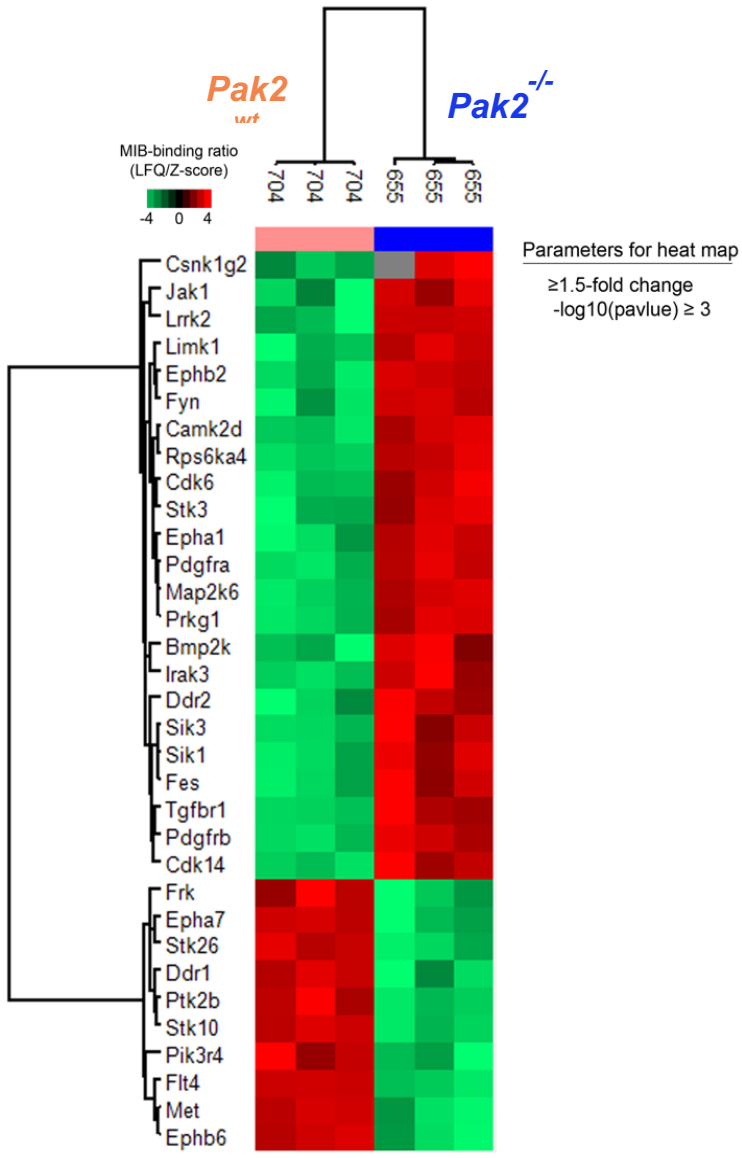
Fig. 7

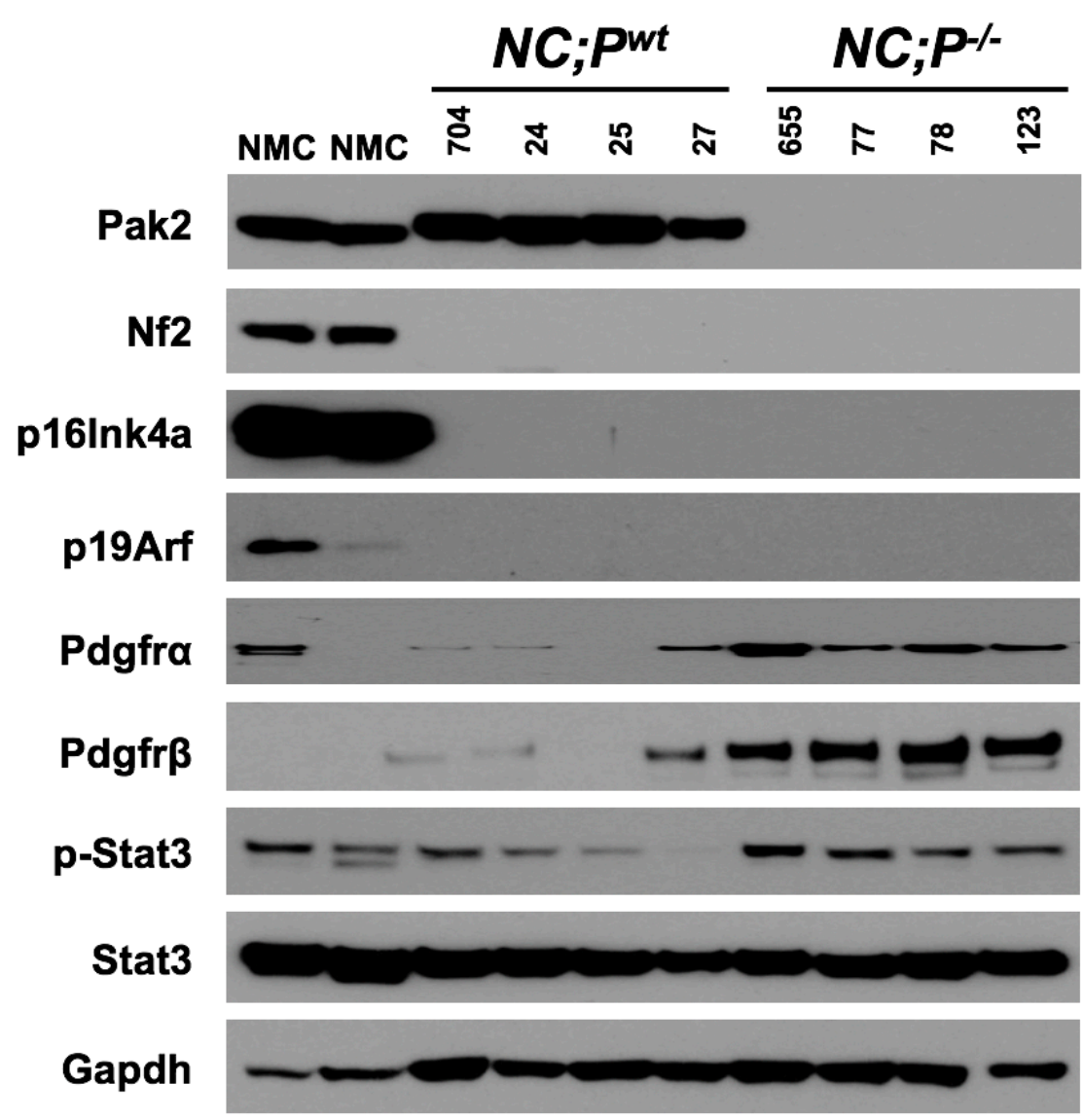

